\title{
"Just Like Me": Improving the Image of Engineering for Elementary School Students
}

\section{Mrs. Jessica Rush Leeker, Purdue University-Main Campus, West Lafayette (College of Engineering)}

Jessica Rush Leeker earned her undergraduate degree from Penn State with a focus in Supply Chain and Information Systems and a minor in international business. She attended Purdue University, receiving an MBA with specialization in Sustainability and Operations.

Before business school, Jessica spent a summer in Haiti, delivering shoes to those in need and creating a more efficient supply chain for urban water projects. Jessica has worked for many successful consumer product companies including Unilever, and Georgia Pacific.

Currently, Jessica is completing her Ph.D. in Engineering Education at Purdue University to focus on practical methods of corporate outreach in STEM for minority communities. In her free time, writes children's books, teaches yoga to children, and enjoys her family.

\section{Kayla R. Maxey, Purdue University-Main Campus, West Lafayette (College of Engineering)}

Kayla is a doctoral student in the School of Engineering Education at Purdue University. Her research interest includes the influence of informal engineering learning experiences on diverse students' attitudes, beliefs, and perceptions of engineering, and the relationship between students' interests and the practices and cultures of engineering. Her current work at the FACE lab is on teaching strategies for K-12 STEM educators integrating engineering design and the development of engineering skills of K-12 learners.

Dr. Monica E. Cardella, Purdue University-Main Campus, West Lafayette (College of Engineering)

Monica E. Cardella is the Director of the INSPIRE Research Institute for Pre-College Engineering and is an Associate Professor of Engineering Education at Purdue University.

\section{Dr. Morgan M. Hynes, Purdue University-Main Campus, West Lafayette (College of Engineering)}

Dr. Morgan Hynes is an Assistant Professor in the School of Engineering Education at Purdue University and Director of the FACE Lab research group at Purdue. In his research, Hynes explores the use of engineering to integrate academic subjects in K-12 classrooms. Specific research interests include design metacognition among learners of all ages; the knowledge base for teaching K-12 STEM through engineering; the relationships among the attitudes, beliefs, motivation, cognitive skills, and engineering skills of K-16 engineering learners; and teaching engineering. 
"JUST LIKE ME": IMPROVING THE IMAGE OF ENGINEERING FOR ELEMENTARY

SCHOOL STUDENTS (RESOURCE EXCHANGE) | UNIT GRADE LEVEL: 3-5

JESSICA RUSH LEEKER, PURDUE UNIVERSITY | RUSH7@PURDUE.EDU

KAYLA MAXEY, PURDUE UNIVERSITY | CARTE231@PURDUE.EDU

DR. MONICA CARDELLA, PURDUE UNIVERSITY | CARDELLA@PURDUE.EDU

DR. MORGAN HYNES, PURDUE UNIVERSITY | HYNESM@PURDUE.EDU

A myriad of factors contributes to the disproportionately low representation of racially and ethnically diverse students participating in engineering. Informal learning environments are locations where racially and ethnically diverse students can experience STEM activities in culturally-relevant and culturally-responsive ways. Identity portraits are a tool for increasing the awareness of the contributions of African Americans, Latinx, and Hispanic professional to the field of engineering. They also allow racially and ethnically diverse students to see images of engineers that they can relate to.

"Just Like Me" identity portraits are a resource created for the National Society of Black Engineers (NSBE)'s Summer Engineering Experience for Kids (SEEK) program, a three-week

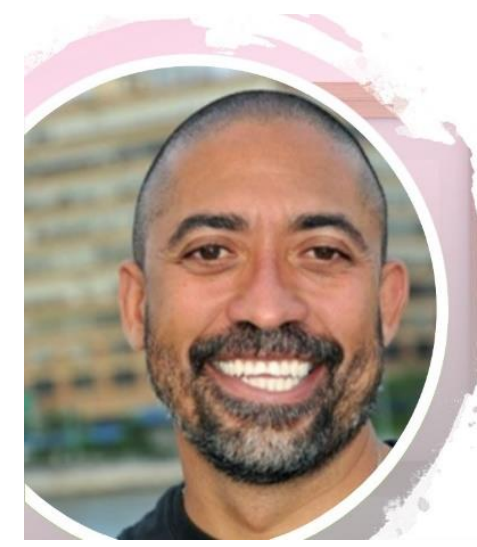

Alan Emtage invented the

world's first search engine.

His idea led to Google and

Yahoo!

Focus:

Computer
Engineering
STEM camp for children who have just completed third through fifth grade. These identity

portraits are a transformative resource to be displayed in each classroom as an informal reminder of recent examples of minority engineers.

Having identity portraits in the classroom allows

students and teachers to pause and read the stories, so everyone can commemorate the achievements made by all individuals and focus on different aspects of the narrative of minorities. The identity portraits feature a relatable photograph of each engineer as well as a

quick description of their work. Age and birthdates were excluded as this information was not found necessary for students.

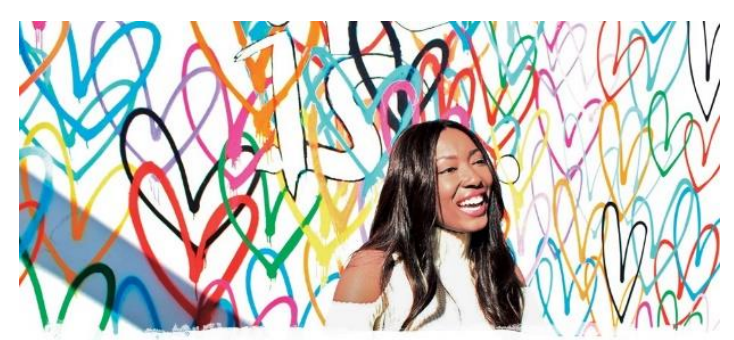

Aisha Bowe creates software solutions for government and corporations. Also, she works hard to close the Focus: Aerospace Engineering

The history of minorities in the United States belong to everyone despite race. The impact minority Americans have made on the United States needs to be a part of collective consciousness. To date, these positive representations are limited to discussions during Black history month or other cultural awareness celebrations which marginalize these populations from the dominant narrative. All too often, only the most harmful aspects of minority culture and communities are highlighted and viewed. 